\title{
Research on Ways of Private Enterprises in Participating in New Urbanization of Zhengzhou City
}

\author{
Yanna $\mathrm{He}$ \\ School of Business Administration \\ Henan Institute of Education \\ Zhengzhou, Henan, China, 450046
}

\begin{abstract}
The urbanization construction of Zhengzhou city plays an exemplary role in the development of Henan province. This article summarizes the periodic achievements made by urban construction of Zhengzhou city and problems derived from rapid development, analyzes the mutual promoting relationships between private enterprise and the urbanization construction of Zhengzhou city, and obstacle factors faced by private enterprises in participating in the construction of urbanization in Zhengzhou city, and then discusses the ways of private enterprises in participating in the construction of urbanization in Zhengzhou city from two perspectives of government and private enterprise.
\end{abstract}

Keywords—private enterprises; Zhengzhou; urbanization

\section{INTRODUCTION}

Statistics show that in 2013, the urbanization rate of permanent resident population in Henan is about 44 percent, which lags behind 53.73 percent of the average level in China. As the capital of Henan province, Zhengzhou city guides Henan province to participate in domestic and overseas competition and bears primary responsibilities in the construction of Central Plains Economic Region. Promoting new-type urbanization is an inevitable requirement to implement the strategy of metropolitan area of Zhengzhou city and construct "one region and the city with two features". It also has relationship with the development of the whole Central Henan urban agglomeration and the Central Plains Economic Region.

\section{CURRENT SitUATION OF URBANIZATION CONSTRUCTION IN ZHENGZHOU CITY}

\section{A. Achievements of Urbanization Construction in Zhengzhou City}

Through exploration and practice, starting from the local reality, giving full play to the comparative advantages of location and resources, Zhengzhou city has walked out a road of new-type urbanization development that suits itself and achieved periodic achievements.

1) Aggregation ability of urban areas is improved. The population aggregation levels of urban area in Zhengzhou and regions and cities at the country level under its administration are continuously promoted. It basically forms the pattern of subjective form of Central Henan urban agglomeration and harmonious development in large, medium and small towns. In 2011, there were 8.86 million people in Zhengzhou city. The per capita GDP reached eight thousand dollars and the urbanization rate reached 67.1 percent. In 2012, the GDP of the whole year reached 554.7 billion. Zhengzhou city entered the key stage of accelerated development of urbanization, accepted internationally. [1] In 2013, the permanent resident population in central urban area of Zhengzhou was more than three million. The floating population is in progressive increase at the speed of twentyfive percent every year. [2]

2) The driving effects of central city increase. Zhengzhou downtown and core towns attract and gather a large number of talents and industrial investment projects. Through insisting on the central city driving strategy, integrating and promoting the development of key areas, [2] Zhengzhou city newly adds some industrial cluster districts and development areas. In 2001, Li Keqiang planed, promoted and launched Zhengdong New District, especially the CBD. After more than ten years of construction, it has become the symbol of enormous development of Henan as well as Zhengzhou city. As the central finance and business district, together with Longzihu District, Baisha District and Zhengzhou Airport Economic Experimental Zone, it commonly forms the central growth pole of Central Plains Economic Region.

3) Urban planning and layout are adjusted. Zhengzhou makes and finishes the spatial layout planning of harmonious and scientific development of "three conversions", determines spatial arrangement of Zhengzhou metropolitan area of "one city, three districts, four groups, 38 industrial cluster districts, 27 new towns, 183 new-type rural communities and 56 villages with historical and cultural features and characteristics". [1] Six (counties) cities and Shangjie District have launched and constructed 204 of four types of community. The five districts in Zhengzhou downtown have implemented 62 projects of urban village renovation, 35 projects of reconstruction of old city and 17 projects of merging village and city. Four management committees totally launched 12 projects of urban village renovation, 31 projects of merging village and city, and 52 projects of village demolition in 2012. [1] In March 15, 2009, the session of national urban village renovation held in Zhengzhou. "Zhengzhou Mode" gains fame and success 
throughout the country. Related officials from many provinces and cities successively come to Zhengzhou to "learn experience".

4) Urban construction is gradually improved. Comprehensive improvement has promoted the construction of some transformer substations, elementary and secondary schools and petty street gardens, improved the production and living environment of the masses, expanded urban construction space and strengthened the infrastructure construction in the city. The first phase of Metro Line 1 operates as scheduled. Zhengzhou steps into the subway age. The main urban districts build and use the three-ring rapid backbone project, speed up constructing the rapid backbone road network of "tic-tac-toe and loop line", and accelerate advancing the project of unblocked Zhengzhou. Engineering such as the "two ring roads and thirty-one roads of radial pattern", 16 belt expressways, 188 dead end highway, and 751 intersection canalizations advances orderly. It newly reconstructs 498 kilometers of county road network. The construction of ecological corridor newly adds green area of $15,200,000$ square meters.

With the infrastructure construction of the city, the framework of Zhengzhou is widened. It lays the foundation for the upgrade of the city in the future to accommodate more people.

\section{B. Problems Existed in the Urbanization Construction in Zhengzhou}

1) The task of urbanization of Zhengzhou is heavy. With the modernization of agriculture, a large number of surplus agricultural populations in each city of Henan province flock to Zhengzhou, the provincial capital. It appears the tendency that the population excessively concentrates in Zhengzhou downtown. By the end of 2013, there were more than 26 million peasant-workers. Before 2020, there will be more than ten million rural residents who will transfer to the city. The built up area in the city needs to rebuild more than two million of urban villages and shanty towns. [4] However, because the bearing capacity of the city is limited, a great many of peasant-workers who flock to the city cannot enjoy urban welfare.

2 ) Problems related to city disease in Zhengzhou city appear. The unilateral cognition that "enclosing the land and constructing buildings, it will be urbanization if peasants move into communities" makes the vacancy rate of houses developed in the new districts in Zhengzhou is relatively high. The narrow numeral indexes cause projects manufactured in a rough way. The urban villages with high density of population reconstruct at the same time. It will be challenges for planning management, use of land, displacement and resettlement of original residents and the "settlement" of external population. Problems such as high house price, blocked traffic and polluted environment make the environment and quality of city life decrease continuously. In 2015, the air pollution index in Zhengzhou is listed in the front rank, even ranks first.
3 ) The support of primacy ratio of Zhengzhou city is weak. The economic primacy ratio of Zhengzhou is low and it has no advantages in aspects such as attract investment and introduce foreign capital. In 2014, the China Business News analyzed the proportion of economy of provincial capital in 27 provinces (excluding municipalities directly under the central government) and found that the proportion of economy of provincial capital in 15 provinces exceeded 25 percent and the proportion of economy of provincial capital in 10 provinces exceeded 30 percent. Among them, the proportion of Wuhan reaches 35.95 percent, and Chengdu 35.4 percent. Both of them exceed one third of the whole province. The data released by Zhengzhou Statistical Bureau in February 2015 shows that the economic aggregate of Zhengzhou accounts for 19.4 percent of the whole province. [5] If we rank the "top 100 Henan private enterprises in 2015" according to operation revenue, we will find that among the top 10 private enterprises, there are three enterprises in Xuchang, two in Nanyang. Tianrui Group that ranks the first is located in Ruzhou city. Only Yutong Group that ranks the third is located in Zhengzhou. [6] It does not conform to the leader position of Zhengzhou that leads the economic development in Henan province.

\section{THE INEVITABILITY AND OBSTACLES OF PRIVATE ENTERPRISES IN PARTICIPATING IN THE NEW-TYPE URBANIZATION CONSTRUCTION IN ZHENGZHOU CITY}

\section{A. Inevitability of Private Enterprises in Participating in the New Urbanization Construction of Zhengzhou City}

Private enterprises in Zhengzhou focus on secondary industry, namely the manufacturing industry. Traditional industry enterprises, resource-based enterprises and preliminary working enterprises are still in the majority. The industrial level is excessively heavy and low. One of the reasons why a large amount of private enterprises can develop smoothly and grow stronger and stronger is that they have land resources hidden and undeveloped, strong support of surplus labor and a steady stream of raw material supply. [7]

The urbanization construction contains enormous business opportunities and brings chances for the development of private enterprises. It is the new opportunity for private enterprises to adjust their industrial structure. In terms of labor supply, Henan province is located in inland. There are a large number of surplus rural populations and the price of labor power is relatively cheap. Enterprises can depend on the advantages of labor resources to expand labor intensive products. In terms of investment chance, the urbanization level of Zhengzhou is relatively low and there are many construction and renovation projects. Both of them leave a lot of investment space for enterprises. In terms of consumption needs, as the capital of a large province with population of 100 million, Zhengzhou city accommodates a large number of people, who will inevitably release enormous consumption needs. In March 2006, Yanzhuang is demolished and reconstructed. It is the symbol that Zhengzhou enters the era of large-scale urban village renovation. Shenglong Group successively turns Yanzhuang 
into Manhattan business circles. Afterwards, it develops large urban complexes such as Shenglong International Center near Daxue Road and Zhengtong Road. In September 6, 2015, "The Pearl of Zhengzhou and Kaifeng, Charm Zhongmou-2015 Zhongmou New-type Urbanization Development Forum" opened in Zhongmou. The forum attracts not only many well-known enterprises and real estate enterprises such as Vanke, Hengda, Greenland Group, Country Garden Holdings Company Limited, and Poly, China Resources, Central China Real Estate Limited, but also senior executives of more than 10 international hightech enterprises from Beijing China, Hong Kong and America to attend. [8]

The new-type urbanization construction needs the participation of private enterprises. With the continuous expansion of urban space and population size, the requirements for urban public infrastructures and public services such as transportation and education are increased continuously. It cannot meet the large investment demands only depending on the government financing platform and band credit. Urbanization needs enriching by private enterprises to further improve level, quality and fund-used efficiency of urban construction. [9] Through decades of struggles, private enterprises in Zhengzhou have accumulated abundant capitals now. In 2014, the top 100 private enterprises in Henan newly added 33.571 billion of fixed-asset investment. Among them, fifty enterprises have major projects that go into operation. Eighteen enterprises achieve major technological breakthrough. Fourteen enterprises have major assets restructuring. The data show that the total amount of rate payment of top 100 private enterprises in Henan in 2014 was 17.084 billion, with yearon-year growth of 4.45 percent. They recruit employers of 339,400 , with year-on-year growth of 12.13 percent. [10] These fully reinforced private enterprises are indispensable important financing powers to promote the new-type urbanization construction. They attract a large number of surplus labor forces and let "new citizens" acquire incomes through their own labors.

The private enterprises contain new development opportunities and have both investment strength and investment demands. There is no doubt that they are the sources of continuous financial resources and powerful supports to continuously promote the urbanization construction and will inevitably continue to promote the development process of new-type urbanization.

\section{B. Obstacles Faced by Private Enterprises in Participating in the New Urbanization Construction of Zhengzhou City}

The enterprises have scarce capacity. The development of private enterprises in Zhengzhou city mainly depends on continuously increasing capital, labor force and resources and lacks the geographical advantages of coastal cities. Compared with first-tier cities and coastal developed areas, most private enterprises in Zhengzhou are at the low end of the industrial chain, with small scale, inadequate technical contents and no strong brand consciousness and lack of corresponding strength and competitiveness. In aspects such as financing and management, they slightly lag behind and lack innovation abilities. Because of the limitations of scale and strength of private enterprises, they cannot receive more labor forces and give relatively generous treatment for employees and then make bigger contributions for the urbanization construction of Zhengzhou city.

The participation platform and encouragement policies are imperfect. Although there are related policies to encourage private enterprises to participate in the new-type urbanization construction, in specific operation, it lacks corresponding platforms and more targeted and feasible encouragement policies. Relevant measures for the implementation and supportive measures are not implemented. These problems make the investments of private enterprises cannot meet the requirements of government and have bad impact on private enterprises to participate in new-type urbanization construction. For example, since 1997, Zhengzhou city has introduced laws and policies to encourage private enterprises to participate in urban afforestation, but it attracts few enterprises. Except for the reasons that private enterprises consider the cost and are not willing to invest, the government also lack publicity and guidance, and cannot formulate specific rules and regulations and effective management methods to attract enterprises.

\section{WAYS OF PRIVATE ENTERPRISES TO PARTICIPATE IN THE NEW-TYPE URBANIZATION CONSTRUCTION IN ZHENGZHOU CITY}

\section{A. Perspective of the Government}

Government of Zhengzhou city can reasonably guide private enterprises to participate in the construction in fields such as urban infrastructure and public service facility to meet the huge investment demands of new-type urbanization construction.

1) Highlight the function of government in planning and reform. Scientific and reasonable planning is the necessary guarantee to promote the sustainable and healthy development of new-type urbanization. The government should base on practical situation of Zhengzhou city, seize strategic opportunities of development of the country and Henan province, adjust measures to local conditions and form scientific and systematic planning; make the best of regional advantages and guide all cities and towns to go the road of urbanization full of characteristics; focus on industrial parks and key towns with developed industry, use industrialization to drive urbanization. [11] In addition, they should also improve the construction and planning of supporting public service facilities and invest more into the construction of public service facilities in the fields such as culture, education and health. As the national level experimental unit of new-type urbanization, Xinzheng always grasps the principle that "takes the urbanization of people as the core, breaking urban-rural dual structure as the objective, releasing domestic demand as the power, reform and innovation as the guarantee", such as carry out four modes of "residence + rental housing, residence + shops, residence +standard workshop, and residence + using land or hosing estates to become shareholder" for peasants. Each 
household can own two sets of house property. One set is for self-occupation; the other set can be rented to enterprises with the help of government. In this way, the peasant can be landlord as well as shareholder. [12]

The government should reform the system of land use and support middle-sized and small cities and small towns to undertake industry transfer; establish and improve the system and mechanism of property transfer transaction in rural areas, introduce relevant policies unrestricted flow of urban and rural production factors, formulate enforcement regulations related to the free transfer of house, house site and contracted land of peasants and let urban residents go to rural areas to undertake agricultural production and management, break the dual system that impedes the unrestricted flow of urban and rural production factors, truly turn the resources of peasants into capitals, let social funds flow to the countryside to help the peasants to make money. Through merging points, towns and cities, Zhengzhou city merges scattered natural villages into towns or communities; set up labor service companies to serve surplus labor; develop and utilize vacated land to make the peasants enjoy land transfer funds after removal. In this way, on one hand, it provides more employment opportunities for rural labor force and improves the service efficiency of production factors such as land, etc. On the other hand, it promotes the urbanization construction. The peasants move into communities and the infrastructure and living conditions improve. They can not only go to farmland to do farm work, but also work in factories to make money. It meets the requirements of peasants. [13]

2) Create good policy environment. The government should actually reduce the entry conditions for private economy to participate in urbanization construction; reform the administrative approval system, increase the finance and taxation support, give equitable treatment for private enterprises; formulate feasible and corresponding policies and measures for private enterprises, attract more private enterprises to participate in urbanization construction, and enter the construction projects of urban infrastructure and public service facilities; help private enterprises to solve financial problems in participating in urbanization construction. Through ways of setting up government special funds or financial aids, the government should support the development of private enterprises, such as the banks preferentially support and the government preferentially support private enterprises to participate in projects of urbanization construction to ensure the interest and efficiency of the investment. In 2015, Zhengzhou city concludes and signs strategic cooperation framework agreement with nine well-known subordinate enterprises under China Minsheng Investment and will respectively invest in software industrial parks, medial institutions, environmental protection equipment, new energy and new material project, infrastructure, cultural industry and international education industry, modern agriculture project, and projects such as industrial ecological garden of crossborder electronic commerce based on mobile internet. [15]

3) Promote private enterprises to implement industrial clusters. The government should promote industrial clusters, accelerate the construction of public service in nesting zone of private enterprise and improve the infrastructure construction of private enterprise and improve the construction of production and operation zone of private enterprises. The government of Zhengzhou city insists introducing talents, sets up industrial investment fund and venture capital fund, introduces supporting policies, uses the innovation and entrepreneurship complex that integrates "two machines and one park" of incubator, accelerator, science and technology innovation park, and scientific and technological enterprises as the carriers, accelerates advancing the construction of scientific and technological independent innovation system with combination of "enterprise, education and training organization, scientific research institution, government, fund raising institution and intermediary service institution", actively establishes independent innovation demonstration area and national level high-tech zone of Central Henan urban agglomeration and continuously strengthens the innovation-driven endogenous motive force of development. [16] In recent years, Xinzheng city has guided enterprises and factories with low additional values to cluster new district, industrial cluster district and specialized park. The industrial cluster development and concentrated development directly promote the employment of 100,000 people and attract 80,000 migrant workers. At present, in Xinzheng, there are 299 industrial enterprises above designated size, 235 enterprises with more than a hundred million of sales revenue, 71 enterprises with above five hundred million, 27 enterprises with above one billion and three marketing enterprises. Since Xinzheng city implements the three years of action plan of new-type urbanization construction in 2012, the gross regional domestic product has increased from 43.955 billion yuan to 56.85 billion yuan in 2014 , with the growth rate of 29.3 percent; the local public financial budget revenue has increased from 2.157 billion yuan to 5.01 billion yuan, with the growth rate of 132.4 percent. In the first half of 2015, Xinzheng finishes the gross regional domestic product of 28.2 billion yuan and local public financial budget revenue of 3.08 billion yuan. [12]

\section{B. Perspective of Private Enterprises}

If private enterprises want to play the leading role in the process of new-type urbanization, it is necessary to improve their abilities and promote the integral level of them.

1) Cultivate the strategic thinking competence of entrepreneurs. If private enterprises want to play a positive role in boosting the new-type urbanization construction, entrepreneurs must grasp the development tendency and go with the tide of historical development. They should pay close attention to the development planning of the country and regional development policies and orientation, analyze the opportunities and threats brought by the environment for enterprises; know well about their advantages and disadvantages, correctly find their positioning, choose appropriate opportunity and entry point, formulate proper methods and steps to boost step by step. By 2016, the rapid transit pattern supported by "two main lines and three cities" (main line railway, arterial highway, inter-city rail transit, inter-city rapid passenger traffic passage and inter-city rapid 
commodity transport passage) will be formed between Zhengzhou and Xinxiang, Jiaozuo, Xuchang to promote the interactive development of industries in Zhengzhou, Kaifeng, Xinxiang, Xuchang and Jiaozuo city, promote the gather of population and industry and build the core region of Central Henan urban agglomeration. Henan province will promote the construction of "three ports and two networks" of air harbor, railway port, road port, rapid railway network and high-grade highway network, and consolidate and promote the position of Zhengzhou as the national comprehensive transportation hub. [12] These planning and strategies are strategic opportunities for private enterprises to accelerate the development. They deserve our great efforts to do indepth research and pay close attention to.

2) Renovate the operation mode of private enterprises. In urbanization construction, it is possible for private enterprises get relevant projects only by taking out different and innovative schemes. They must keep a foothold of reality and conform to conditions of the people, guarantee the quality and service level to ensure the long-term development, such as boosting projects of leisure agriculture, to realize functions of increasing the economic incomes of peasants, driving the local employment, inheriting agriculture civilization and beautifying rural environment, etc. Private enterprises should establish learning organization to train traditional peasant-workers into new-type industrial workers, and must accelerate renewal of ideas and knowledge. They should construct modern enterprise system and shape enterprise culture full of vitality and energy; reform internal management system in enterprise, transfer from "rule of man" to "scientific management"; learn modern science and technology and information technology, increase technological content and pursue technological innovation and the leap of quality; boost the professional and standard industrialization operation to promote the enterprise to realize industrial revolution. Besides, private enterprises need to transform and upgrade operating instruction and mode of operation to increase science and technology level and improve quality and efficiency. [18]

3) Promote the occupational qualities of "new citizens". General Secretary Xi points out that the realization of moderately prosperous society depends on peasants. Solving the problems of people is the key to promote the new-type urbanization. Private enterprises absorb a large number of peasants and realize the employment near the "doorway" to help them to improve the income level and realize the transformation of identity. Private enterprises should pay attention to the vocational training and quality enhancement of peasant-workers, vigorously implement the plan of employment skill improvement for peasant-workers, make each peasant-worker especially the generation after $80 \mathrm{~s}$ and 90s can get at least one training of free basic vocational skills. Take the Jiwang community in Mengzhuang town in Xinzheng city as an example. Previously, the fixed asset per capita of villagers is less than 25,000 yuan. After moving into the new-type community, each household is compensated with 130,000 yuan. The fixed assets per capital reach 250,000 yuan. According to the requirement of "one community with one enterprise" put forward by Xinzheng city, at present, this community has realized local employment of 255 people and drove more than 100 people to start up business and attracted the employment of external population of more than 15,000 . Besides, private enterprises launch free vocational training and occupational guidance for peasants. In 2014, they totally carried out 16 trainings for 7,693 people and finished transfer employment of rural labor force of 17,028. [12]

Introducing private enterprises into new-type urbanization construction can not only make contributions for regional economic development but also create new development challenges for private enterprises.

\section{REFERENCES}

[1] Pei Qijuan. New-type Urbanization Leads the New Brilliance, Zhengzhou Daily, 2013-3-29

[2] Zhang Yu. Three-year Plan of New-type Urbanization to Make the Permanent Resident Population of Central Area in Zhengzhou Doubled in Three Years, Dahe Daily, 2014-07-01

[3] Wu Jianyou. Zhengzhou: New-type Urbanization Leads Magnificent Evolution, China Economic Times, 2013-01-28

[4] Su Huixia. Analysis on the Development of New-type Urbanization of Henan Province, Market Forum, 2015-04-15

[5] Li Yajing, Hu Juyang. Build Zhengzhou into National Key City and Create "International Commercial Metropolis", Henan Business Daily, 2015-03-13

[6] Li Shiding. Among the Top One Hundred Private Enterprises of Henan Province in 2015, Fourteen Enterprises Have over Ten Billion of Operation Revenue, Dahe Daily, 2015-11-09

[7] Sun Zhouping. Discussion on the Role and Function of Private Enterprise in the Construction of New-type Urbanization, Entrepreneurs Daily, 2013-06-11

[8] Liang Xinhui. Provincial Administrative Center Goes All the Way to the East; Attract Real Estate Tycoons Successively Focus on Zhongmou. Orient Today, 201-09-07

[9] Li Haifei, Jin Yong. Research on Problems Faced by Private Enterprises in Participating in the Construction of New-type Urbanization, Review of Economic Research, the 44th edition in 2014

[10] Li Ling. Nanyang, Zhengzhou, Xuchang as the Concentration Areas of Top One Hundred Private Enterprises in Henan Province, Orient Today, 2014-11-10

[11] All-China Federation of Industry and Commerce, Give Play to Advantages of Private Enterprises to Promote New-type Urbanization. qstheory.cn, 2014-03-14

[12] Wu Jun. Exposure of Relevant "Experience" that Xinzheng Becomes National-level Experimental Unit of New-type Urbanization, Henan Business Daily, 2015-10-13

[13] Hu Xiaohui, Wen Chunliu, Zhou Linlin. Thinking on Survey of "New-type Rural Community" Samples of Zhengzhou in Construction of New-type Urbanization, China Radio Network, 201308-15

[14] NPC Member Hu Baosen Suggests: Encourage Nongovernmental Capital to Participate in Urbanization Construction, Sina Finance, March 7, 2014

[15] Wang Jibing, Zhang Qiaopu. Zhengzhou Signs Strategic Cooperation Agreement with Nine Well-known Subordinate Enterprises under China Minsheng Investment, Zhengzhou Daily, 2015-03-31

[16] Zhao Qiang, Zheng Xiaoqian,etc. Build Zhengzhou into National Key City and Create "International Commercial Metropolis", Henan Business Daily, 2015-03-13

[17] How Private Enterprises Can Be More Capable of Making Outstanding Achievements in New Rural Construction, Urbanization 
Construction and Regional Economic Development? Manager Daily, 2011-02-21

[18] Gao Weizuo. Township Enterprises Promote the Development of New-type Urbanization, Farmers' Daily, 2015-02-14 